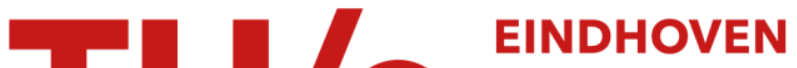 \\ UNIVERSITY OF \\ TECHNOLOGY
}

\section{Simultaneous quality and reliability optimization for microengines subject to degradation}

Citation for published version (APA):

Peng, H., Feng, Q., \& Coit, D. W. (2009). Simultaneous quality and reliability optimization for microengines subject to degradation. IEEE Transactions on Reliability, 58(1), 98-105.

https://doi.org/10.1109/TR.2008.2011672

DOI:

10.1109/TR.2008.2011672

Document status and date:

Published: 01/01/2009

Document Version:

Publisher's PDF, also known as Version of Record (includes final page, issue and volume numbers)

Please check the document version of this publication:

- A submitted manuscript is the version of the article upon submission and before peer-review. There can be important differences between the submitted version and the official published version of record. People interested in the research are advised to contact the author for the final version of the publication, or visit the $\mathrm{DOI}$ to the publisher's website.

- The final author version and the galley proof are versions of the publication after peer review.

- The final published version features the final layout of the paper including the volume, issue and page numbers.

Link to publication

\section{General rights}

Copyright and moral rights for the publications made accessible in the public portal are retained by the authors and/or other copyright owners and it is a condition of accessing publications that users recognise and abide by the legal requirements associated with these rights.

- Users may download and print one copy of any publication from the public portal for the purpose of private study or research.

- You may not further distribute the material or use it for any profit-making activity or commercial gain

- You may freely distribute the URL identifying the publication in the public portal.

If the publication is distributed under the terms of Article 25fa of the Dutch Copyright Act, indicated by the "Taverne" license above, please follow below link for the End User Agreement:

www.tue.nl/taverne

Take down policy

If you believe that this document breaches copyright please contact us at:

openaccess@tue.nl

providing details and we will investigate your claim. 


\title{
Simultaneous Quality and Reliability Optimization for Microengines Subject to Degradation
}

\author{
Hao Peng, Qianmei Feng, and David W. Coit, Member, IEEE
}

\begin{abstract}
Micro-Electro-Mechanical Systems (MEMS) represent an exciting new technology, but to achieve more widespread usage and wider adoption within more industrial applications, they must be highly reliable, and manufactured to stringent quality standards. Many challenging manufacturing issues are of concern during the fabrication of MEMS, such as precise dimensional inspection, reliability modeling, burn-in scheduling, avoiding stiction, and maintenance strategies. However, only limited mathematical tools for improving MEMS reliability, quality, and productivity are currently available. This paper proposes a mathematical model to jointly determine inspection \& preventive replacement policies for surface-micromachined microengines subject to wear degradation, which is a major failure mechanism for certain MEMS devices. The optimal specification limits for inspection, and the replacement interval are determined by simultaneously optimizing MEMS quality and reliability. The proposed model can be used as a tool for decision-makers in MEMS manufacturing to make sound economical and operational decisions on reliability, quality, and productivity. While illustrated considering one specific microengine design, the proposed model can be applied to a broader range of MEMS devices that experience wear degradation between rubbing surfaces.
\end{abstract}

Index Terms-Burn-in, MEMS reliability, preventive replacement, quality and reliability optimization, specification limits, wear degradation.

\section{ACRONYM $^{1}$}

pdf probability density function

cdf cumulative distribution function

MEMS Micro-Electro-Mechanical Systems

NDE Non-Destructive Evaluation

SQP Sequential Quadratic Programming

\section{NOTATION}

$t$ Number of revolutions to failure

$X(t), X(t ; \boldsymbol{\beta}) \quad$ Wear volume of material at $t$ (sometimes expressed as a function of model coefficients ק)

Manuscript received September 16, 2007; revised August 01, 2008; accepted September 13, 2008. First published February 10, 2009; current version published March 04, 2009. The work of H. Peng and Q. Feng was supported by the Grants to Enhance and Advance Research (GEAR) Program at the University of Houston. Associate Editor: L. Cui.

H. Peng and Q. Feng are with the Department of Industrial Engineering, University of Houston, Houston, TX 77204 USA (e-mail: hao_png@yahoo.com; qmfeng@uh.edu).

D. W. Coit is with the Department of Industrial and Systems Engineering, Rutgers University, Piscataway, NJ 08854 USA (e-mail: coit@ rutgers.edu).

Color versions of one or more of the figures in this paper are available online at http://ieeexplore.ieee.org.

Digital Object Identifier 10.1109/TR.2008.2011672

${ }^{1}$ The singular and plural of an acronym are always spelled the same.

\begin{tabular}{|c|c|}
\hline$H$ & Critical wear volume or failure threshold \\
\hline$r$ & Radius of the pin joint \\
\hline$c$ & $\begin{array}{l}\text { Model parameter proportional to the wear } \\
\text { coefficient, and inversely proportional to the } \\
\text { hardness of the material }\end{array}$ \\
\hline$F$ & Force between the contacting surfaces \\
\hline$t_{0}$ & $\begin{array}{l}\text { Burn-in time, or number of revolutions to } \\
\text { burn-in }\end{array}$ \\
\hline$\eta$ & Upper specification limit \\
\hline$L\left(X\left(t_{0}\right)\right)$ & Quality loss function after burn-in \\
\hline$C_{Q}\left(\eta, t_{0}\right)$ & Expected quality loss after burn-in \\
\hline$s$ & Scrap cost per unit \\
\hline$C_{S}\left(\eta, t_{0}\right)$ & Expected scrap cost \\
\hline$C_{I}$ & Inspection cost per unit \\
\hline$Q C$ & Expected quality-related cost \\
\hline$f_{c}$ & Cost of failure per unit \\
\hline$F C$ & Expected failure cost \\
\hline$R C$ & Replacement cost \\
\hline$\tau$ & Replacement time \\
\hline$B_{\tau}$ & Upper bound of the replacement interval \\
\hline$\phi(\cdot)$ & $\begin{array}{l}\text { pdf of a standard normally distributed } \\
\text { variable }\end{array}$ \\
\hline$\Phi(\cdot)$ & $\begin{array}{l}\text { cdf of a standard normally distributed } \\
\text { variable }\end{array}$ \\
\hline
\end{tabular}

\section{INTRODUCTION}

$\mathbf{T}$ O ACHIEVE WIDESPREAD usage, Micro-Electro-Mechanical Systems (MEMS) must be highly reliable, and manufactured to stringent quality standards. MEMS technology shows great promise for many critical applications in aerospace, biological/medical, nuclear, and weapons areas. In addition to new applications enabled by MEMS technology, existing applications are enhanced by miniaturized, low-cost, high-performance, and "smart" MEMS technology. MEMS devices have been effectively used in many commercial products, such as accelerometers in automotive airbag deployment systems [13], and inkjet print heads [29]. With more widespread commercialization of MEMS products, many challenging manufacturing/fabrication issues are of concern including precise dimensional control and inspection, reliability testing and modeling, avoiding stiction, and maintenance strategies. These reliability, quality, and productivity issues are dominant factors that impact the process of MEMS moving from the laboratory into the mainstream market. Decision-makers in MEMS manufacturing need tools to optimize these operational decisions. 
However, such mathematical tools to improve MEMS reliability, quality, and productivity are currently lacking.

This study proposes a mathematical model to jointly determine inspection and preventive replacement policies for the surface-micromachined microengines subject to wear degradation, which is a major failure mechanism in MEMS devices [24], [25]. The optimal specification limits for inspection, and the replacement interval are determined by optimizing MEMS quality and reliability simultaneously.

\section{A. Failure Analysis of MEMS}

Reliability, and quality are important factors for MEMS to evolve from prototypes to commercialization. These issues for MEMS are complicated due to both electronic and mechanical parts, and their interactions [14]. Sufficient understanding of failure mechanisms is required to improve reliability and quality of MEMS devices in critical applications. However, knowledge is still somewhat limited on MEMS failures, and failure causes, at least in the public domain. According to their operational interactions, MEMS devices can be categorized into four classes [22], [23], [30]: Class I devices have no freely moving parts, but may have parts which stretch, compress, or bend, such as accelerometers, pressure sensors, or strain gauges; Class II devices have moving parts without rubbing or contacting surfaces, such as gyros, resonators, and filters; Class III devices have moving parts with contacting surfaces, such as relays, and valve pumps; and Class IV devices have moving parts with rubbing, contacting surfaces, such as shutters, scanners, and optical switches.

Designed with no rubbing surfaces, the first three classes of MEMS devices can achieve a high level of reliability if they are properly manufactured, and packaged. For Class IV MEMS devices, in which rubbing surfaces are unavoidable, failure analysis, and reliability assessment must be performed to further advance the growing commercialization of MEMS. Failure modes, and reliability models of Class IV MEMS were investigated by researchers at Sandia National Laboratories, a leader of MEMS technology [24], [25]. They conducted their research by performing many experiments on a reliability testing infrastructure. The MEMS device used in the reliability testing is a surface-micromachined microengine, developed at Sandia. As shown in Fig. 1, the microengine consists of orthogonal linear comb drive actuators that are mechanically connected to a rotating gear. The linear displacement of the comb drives is transformed to the gear via a pin joint. The gear rotates about a hub that is anchored to the substrate [26].

The dominant failure mechanism is identified as visible wear on rubbing surfaces, which often results in either seized microengines, or microengines with broken pin joints [21], [30]. Wear can be defined as the removal of material from solid surfaces as a result of mechanical actions. Wear degradation is a very complex phenomenon, involving both the mechanical and chemical properties of the bodies in contact, and also the pressure and interfacial velocity under which the bodies make contact.

\section{B. Literature Review on Degradation Processes}

Wear processes are degrading phenomena that have been studied in electronics, and other engineering fields. Lu \& Meeker [16], and Meeker et al. [19] developed general statis-

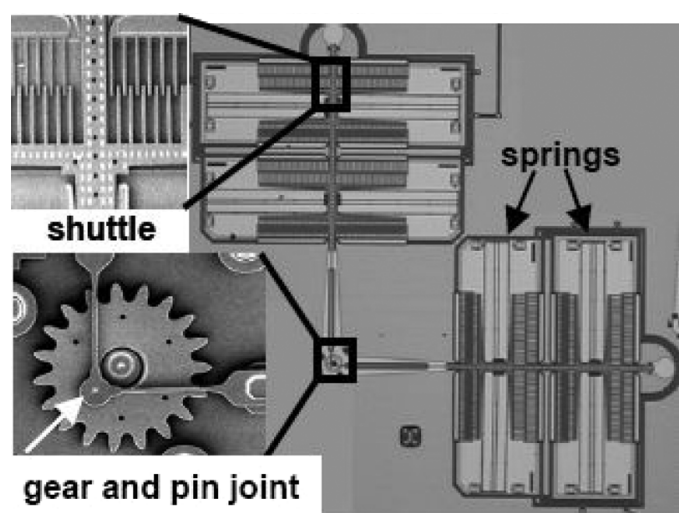

Fig. 1. Scanning electron microscopy image of a microengine [26] (courtesy of SPIE).

tical models to estimate the time-to-failure distribution from degradation measures. A general model, and several examples were provided for the degradation path model. Bae \& Kvam [2] introduced a log-linear degradation model with an unknown change point to characterize nonlinear degradation paths representing incomplete burn-in during the manufacturing process of plasma display panels. Kharoufeh [11] derived the explicit probability distribution of the random failure time for single-unit systems that deteriorate continuously and additively due to the influence of a random environment modeled as a general, finite-state Markov process. Kharoufeh \& Cox [12] presented a degradation-based procedure for the estimation of full, and residue lifetime distribution for single-unit systems using real sensor data. Boulanger \& Escobar [3], Tseng et al. [27], Yu \& Chiao [31], and Joseph \& Yu [10] used experimental design to improve reliability for degradation processes.

For degradation processes, preventive replacement (PR), or preventive maintenance (PM) is often considered as a policy to reduce the number of failures. Many different PR or PM approaches for degrading systems have been studied in the literature. Grall et al. [8] developed a maintenance cost model for determining the optimal inspection schedule and replacement threshold for a single unit degrading system. To reduce the uncertainty in cost estimates, Liao et al. [15] proposed a condition-based maintenance model for a continuous degradation process by considering imperfect maintenance, and a short-run availability constraint. Lu et al. [17], and Lu et al. [18] presented a preventive condition-based maintenance approach based on monitoring, modeling, and predicting a system's deterioration. Drapella \& Kosznik [4] developed a model to seek for equilibrium of burn-in, and preventive replacement periods. Jiang \& Jardine [9] examined the effectiveness of a jointly applied burn-in and preventive replacement policy for situations where the failure time follows a mixture distribution.

\section{Research Objectives and Contribution}

Although many different preventive replacement approaches for degrading systems have been studied, a comprehensive approach to jointly determine the inspection and preventive replacement policies is not available in the literature. For the microengine wear degradation, this paper proposes a mathematical model to jointly determine the parameters for inspection, 
and preventive replacement policies. For systems with degradation characteristics, manufacturing decisions should be determined by taking into account quality at the manufacturing phase, and reliability during system operation, simultaneously. By rewarding high system reliability, and penalizing the quality loss due to variation, the proposed model can determine the optimal specification limits for inspection, and an optimal replacement interval. Although the idea of integrating quality and reliability into system design is not a new concept, there is no existing approach for determining specifications on degradation characteristics to optimize quality and reliability simultaneously. This integrated strategy can reduce warranty cost, and repair cost, while increasing customer satisfaction in the long run.

Only limited mathematical tools for improving MEMS reliability, quality, and productivity are currently available. This paper proposes a model that can be used as a tool for decision-makers in MEMS manufacturing to economically optimize operational decisions on reliability, quality, and productivity, which are critical factors during the fabrication of the microengine. While illustrated using Sandia-developed microengines as examples [24], [25], the proposed model can be applied to a broad range of MEMS devices that experience wear degradation between rubbing surfaces.

\section{MODEL FORMULATION}

Consider a MEMS system containing one microengine that is subject to wear. Furthermore, failure of the microengine causes failure of the system. The failure of the microengine occurs when the wear volume of material reaches a critical threshold, $H$ [24]. This type of failure is referred to as "soft" failures, as opposed to "hard" failures when systems or components stop functioning abruptly. The critical threshold on a wear volume is assumed to be a constant in this study, although it may vary from unit-to-unit. The wear volume of material can be estimated by measuring the volume of wear debris, or the missing volume in the worn device. For example, a Focused Ion Beam system is effective to evaluate the amount of wear debris by producing cross sections of the precise area of interest in MEMS structures [25].

To simultaneously improve quality and reliability over the lifetime of MEMS systems, a systematic inspection and preventive replacement procedure has been developed, as depicted in Fig. 2. The initial wear volume of material after the completion of manufacturing is assumed to be zero, i.e., $X(0)=0$. A burn-in procedure following MEMS manufacturing is used to detect, and remove defective, and early-failed parts. Burn-in is an important process to achieve reliable components and systems, but it also exposes all units to stresses. For the burned-in units, the nondestructive inspection is implemented to screen-out the fraction of units whose wear volumes exceed a certain specification limit. The screened units, with high quality level, are then released for field operation until reaching the periodic replacement time, where the cost of an impending failure makes it economical to replace it with a new one. The preventive replacement procedure is used to prevent failure due to the wear-out of typical operating units.

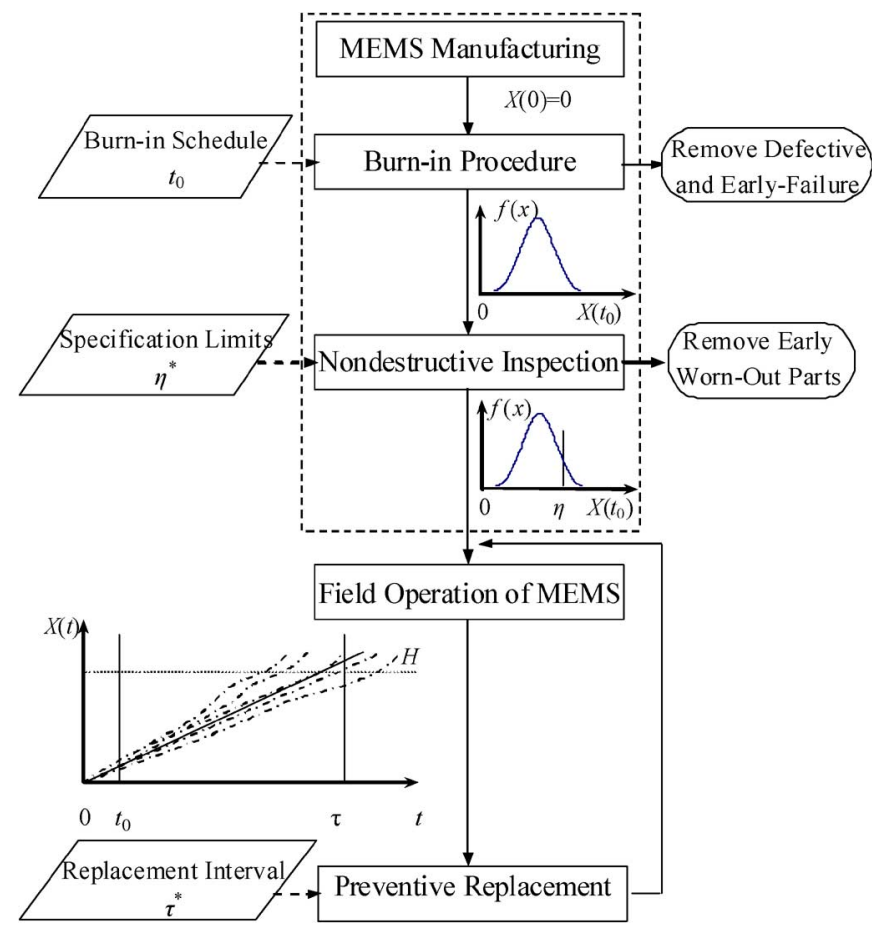

Fig. 2. Burn-in, inspection, and preventive replacement procedures for MEMS.

\section{A. Wear Degradation Model}

Let $X(t ; \boldsymbol{\beta})$ denote the actual degradation path of a degrading characteristic over time $t$, where $\beta$ is a vector of model coefficients. The choice of a degradation model requires not only specification of the form of the $X(t ; \boldsymbol{\beta})$ function, but also specification of fixed and random parameters in $\beta$ [7]. Typically, degradation paths are described by a model with up to four parameters. Some of the parameters in $\beta$ are random from unit-tounit, and one or more parameters could be modeled as constant across all units [19].

For the wear degradation of microengines, the degradation model is derived based on physical theory to quantify the functional relationship between the wear volume, $X(t ; \boldsymbol{\beta})$, and the number of revolutions to failure, $t$ [26]. Given the radius of the pin joint, $r$ (shown in Fig. 1), the coefficient related to wear and hardness of the material, $c$, and the force between the contacting surfaces, $F$, the linear degradation path, $X(t ; r, c, F)$, is shown in Fig. 3, and can be expressed as

$$
X(t ; r, c, F)=2 \pi r c F t .
$$

$c$ is a parameter that is directly proportional to the wear coefficient, and inversely proportional to the hardness of material. The radius of pin joint, $r$, is random from unit-to-unit with mean $\mu_{r}$, and standard deviation $\sigma_{r}$. For a sinusoidal drive signal, the force applied between rubbing surfaces, $F$, varies with drive frequency as the critical frequency for resonance is approached. At a given drive frequency, the force applied between rubbing surfaces is random among units with nominal value $\mu_{F}$, and standard deviation $\sigma_{F}$.

The wear volume at any time $t, X(t)$, is random from unit-tounit, and can be reasonably assumed to follow a $s$-normal distribution. There are many combinations of distributions for $r$, and 


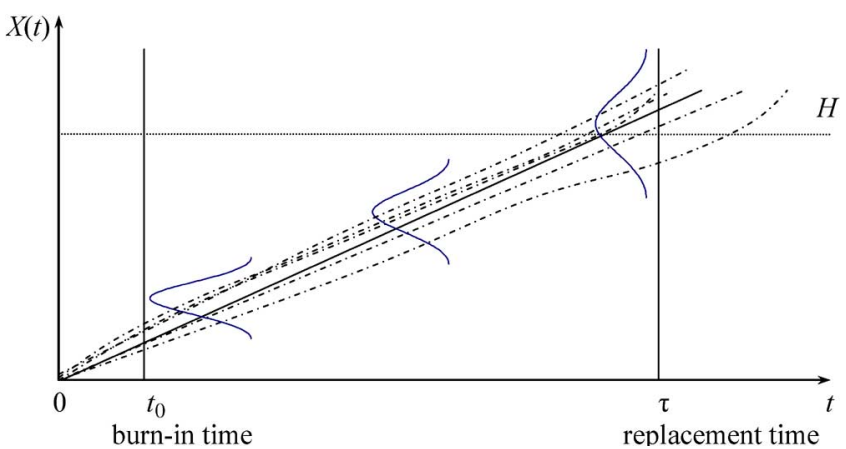

Fig. 3. Linear wear degradation path.

$F$ that will result in a $s$-normally distributed $X(t)$. If a $s$-normal distribution is not appropriate, then transformations can be performed to obtain a $s$-normally distributed random variable. Assuming $s$-independence between $r$ and $F$, it is demonstrated that

$$
\begin{aligned}
\mu_{t} & =2 \pi c \mu_{r} \mu_{F} t, \quad \text { and } \\
\sigma_{t} & =2 \pi c t \sqrt{\sigma_{r}^{2} \sigma_{F}^{2}+\sigma_{r}^{2} \mu_{F}^{2}+\mu_{r}^{2} \sigma_{F}^{2}},
\end{aligned}
$$

which indicates that the mean $\mu_{t}$ changes linearly, and the standard deviation $\sigma_{t}$ increases linearly, over time. At the completion of MEMS manufacturing, but prior to burn-in, $X(0)=0$.

For different degradation characteristics in MEMS or other applications, the functional form of $X(t ; \boldsymbol{\beta})$, and the approximate transformation may be suggested by physical or chemical theory, past experience, or the available data. When the degradation path is not linear, the scales of $X(t)$, and $t$ can be chosen to simplify the form of the degradation model. For many problems, the Box-Cox family of transformations will be useful, especially the log transformation of degradation and/or time [19].

\section{B. Burn-In Procedure}

It is observed through experiments that the occurrence of microengine failures consistently decreases at the early stage of testing, which indicates infant mortality caused by the early failures of defective parts [24]. This implies that a burn-in procedure should be applied following the manufacturing process to effectively remove weak devices from the population. The burn-in process is an extension of manufacturing processes where manufactured units are operated for a short period of time to screen-out defective parts. The burn-in time, $t_{0}$, must be determined to prevent the early failures. Selection of the burn-in time is made based on a combination of test data, industry standards, and time restrictions. In this paper, the burn-in time is determined prior to the optimization of the quality tolerance level, and replacement time.

The need for shorter production cycles drives MEMS manufacturers to reduce the burn-in time. However, if the burn-in is incomplete, the microengine may experience unacceptable early failures. An effective burn-in schedule should be determined that it is long enough to induce the defective units to fail, but not too long to impinge on the required lifetime of engines. Further study on burn-in procedure is necessary to incorporate the cost of burn-in procedure into the model, which includes the operating cost of the burn-in equipment, the failure cost during the burn-in process, and marketing losses caused by increased production lead time.

\section{Nondestructive Evaluation, and Specification Limits}

As wear is the most critical failure mode for the microengine, the wear volume should be carefully evaluated at the end of the burn-in procedure. The units whose wear volumes are beyond a certain specification limit are prone to fail early, and they should be screened to ensure that the wear volume does not unsatisfactorily reduce the lifetime of microengines. Nondestructive evaluation (NDE) systems can be implemented to provide $100 \%$ inspection capabilities, such as Focused Ion Beam systems.

At the end of the burn-in procedure, $t_{0}$, the wear volume is given as $X\left(t_{0}\right)=2 \pi r c F t_{0}$, which follows a $s$-normal distribution, $X\left(t_{0}\right) \sim N\left(\mu_{0}, \sigma_{0}^{2}\right)$, where $\sigma_{0}^{2}=(2 \pi c)^{2}\left(\sigma_{r}^{2} \sigma_{F}^{2}+\sigma_{r}^{2} \mu_{F}^{2}+\right.$ $\left.\mu_{r}^{2} \sigma_{F}^{2}\right) t_{0}^{2}$, and $\mu_{0}=2 \pi c \mu_{r} \mu_{F} t_{0}$, respectively. During the NDE, an upper specification limit (USL) should be applied based on the wear volume, to screen the units that have a large amount of wear after the burn-in process. The selection of the USL is a crucial decision that is usually determined by optimizing the quality of a system [5], [6]. However, this may be inefficient for the manufacturing of new technologies such as MEMS because of the degradation process, and reliability concerns. Therefore, quality and reliability should be integrated in the optimization of specification limits.

During the NDE, three quality-related costs are considered: quality losses due to the deviation from the ideal value, scrap or rework cost, and inspection cost [5]. The quality loss of each unit can be measured by a quality loss function, which can be chosen based on the type of the quality characteristic: the smaller the better (S-type), the larger the better (L-type), or the target the best (T-type). The wear volume is clearly an S-type quality characteristic, and its quality loss function is expressed as

$$
L\left(X\left(t_{0}\right)\right)=k X\left(t_{0}\right)^{2},
$$

where $k$ is the coefficient that transforms deviations into economic values. The quality loss can be estimated using the expected value of $L\left(X\left(t_{0}\right)\right)$. Based on the derivation of the expected quality loss for the T-type characteristic provided in Feng \& Kapur [6], the expected quality loss for the S-type characteristic, $C_{Q}(\eta)$, is proven to be

$$
\begin{aligned}
C_{Q}(\eta)= & \int_{0}^{U S L} L\left(x ; t_{0}\right) f_{X\left(t_{0}\right)}\left(x ; t_{0}\right) d x=\int_{0}^{\eta} k x^{2} f_{X\left(t_{0}\right)}\left(x ; t_{0}\right) d x \\
= & -k \sigma_{0}\left[\mu_{0}+\eta\right] \phi\left(\frac{\eta-\mu_{0}}{\sigma_{0}}\right)+\sigma_{0} \mu_{0} k \phi\left(\frac{-\mu_{0}}{\sigma_{0}}\right) \\
& -k\left[\sigma_{0}^{2}+\mu_{0}^{2}\right] \Phi\left(\frac{-\mu_{0}}{\sigma_{0}}\right)+k\left[\sigma_{0}^{2}+\mu_{0}^{2}\right] \Phi\left(\frac{\eta-\mu_{0}}{\sigma_{0}}\right),
\end{aligned}
$$

where $f_{X\left(t_{0}\right)}\left(x ; t_{0}\right)$ is the pdf of the wear volume at the end of the burn-in process.

If an observed measurement is outside the USL, the unit will be reworked or scrapped. Let $q(\eta)$ be the fraction of 
conforming units, which corresponds to the area under the pdf curve bounded by the USL.

$$
q(\eta)=\int_{0}^{\eta} f_{X\left(t_{0}\right)}\left(x ; t_{0}\right) d x=\Phi\left(\frac{\eta-\mu_{0}}{\sigma_{0}}\right)-\Phi\left(-\frac{\mu_{0}}{\sigma_{0}}\right) .
$$

If the scrap/reworked cost per unit is denoted as $s$, then the scrapped portion of $(1-q(\eta))$ results in an expected scrap cost of $(1-q(\eta)) s$. Thus, the expected scrap cost is

$$
C_{S}(\eta)=(1-q) s=\left(1-\Phi\left(\frac{\eta-\mu_{0}}{\sigma_{0}}\right)+\Phi\left(-\frac{\mu_{0}}{\sigma_{0}}\right)\right) s .
$$

The inspection cost per unit is denoted as $C_{I}$, which is a constant independent of $\eta$. Therefore, the total expected quality cost per unit incurred at the manufacturing is expressed as

$$
Q C(\eta)=C_{Q}(\eta)+C_{S}(\eta)+C_{I}
$$

\section{Preventive Replacement, and Cost of Failure}

A preventive periodic-replacement policy is used to prevent failure due to the wear-out of typical operating units. As the system ages, it is more economical to replace an aged system because the cost of a planned replacement is less than the associated cost of unscheduled maintenance. The microengine fails when the wear volume of material reaches a critical threshold, $H$. Therefore, the reliability of a microengine at any time $t$ (or number of cycles) can be assessed by the probability that the wear volume is less than the failure threshold, i.e.,

$$
R(t)=P(X(t)<H)=\int_{0}^{H} f_{X(t)}(x ; t) d x=\Phi\left(\frac{H-\mu_{t}}{\sigma_{t}}\right) .
$$

This equation is valid when the wear volume follows a $s$-normal distribution, i.e., $X(t) \sim N\left(\mu_{t}, \sigma_{t}^{2}\right)$. If another distribution is more suitable, an analogous relationship can be derived. The reliability at any time $t\left(t_{0}<t<\tau\right)$, is measured as a conditional reliability given the probability that the wear volume during the burn-in process is less than $H$, or

$$
R\left(t \mid t_{0}\right)=\frac{P(X(t)<H)}{P\left(X\left(t_{0}\right)<H\right)}, \quad t_{0}<t<\tau .
$$

To be consistent with the monetary measure of quality costs measure, the system reliability can be evaluated considering the cost-of-failure approach [28]. The cost of failure per unit is assumed to be a constant, $f_{c}$, which is $s$-independent of the time to failure, and can be estimated by a one-year warranty cost, or a one-time repair cost. The system reliability at the time of replacement is then evaluated by the expected failure cost:

$$
F C(\tau)=f_{c}\left(1-R\left(\tau \mid t_{0}\right)\right)
$$

If the system fails prior to $\tau$, then it must be replaced by an operational replacement, and the cost is $f_{c}+R C$, where $R C$ is the replacement cost. Alternatively, if it has not failed by $\tau$, it should be replaced based on economic considerations, and the cost is just $R C$. Thus, the expected total failure plus replacement cost at $\tau$ is $F C(\tau)+R C$.

\section{E. Simultaneous Quality and Reliability Optimization Model}

By simultaneously rewarding high reliability during system operation, and penalizing quality loss during manufacturing, a comprehensive model is proposed to determine the specification limit for inspection, $\eta$, and the replacement interval, $\tau$. The expected total system cost includes the expected quality cost, failure cost, and replacement cost, which should be minimized over the expected usage time of a microengine. The expected usage time, $E\left[U \mid t_{0}, \tau\right]$, is demonstrated to be (see the Appendix)

$$
\begin{aligned}
E\left[U \mid t_{0}, \tau\right] & =\int_{0}^{\tau-t_{0}} R\left(t+t_{0} \mid t_{0}\right) d t \\
& =\frac{1}{R\left(t_{0}\right)}\left(\tau R(\tau)-t_{0} R\left(t_{0}\right)+\int_{t_{0}}^{\tau} t f_{T}(t) d t\right),
\end{aligned}
$$

where $f_{T}(t)$ is the pdf of the failure time with the form

$$
f_{T}(t)=\frac{H}{\sqrt{2 \pi} b t^{2}} e^{-\frac{(H-a t)^{2}}{2 b^{2} t^{2}}},
$$

with

$2 \pi c \mu_{r} \mu_{F} \quad$ and $b=\sqrt{(2 \pi c)^{2}\left(\sigma_{r}^{2} \sigma_{F}^{2}+\sigma_{r}^{2} \mu_{F}^{2}+\mu_{r}^{2} \sigma_{F}^{2}\right)}$. This is the pdf for a two-parameter Bernstein distribution [1].

In this way, the expected total system cost per unit expected usage time is given as

$$
T C(\eta, \tau)=\frac{Q C(\eta)+F C(\tau)+R C}{E\left[U \mid t_{0}, \tau\right]} .
$$

In practice, the upper bound of the replacement interval is usually specified, and is denoted as $B_{\tau}$. Thus, the constrained optimization model that minimizes the expected total system cost rate due to quality loss, and unreliability during the system life cycle, can be expressed as

$$
\begin{aligned}
& \left(\eta^{*}, \tau^{*}\right)=\arg \min \left\{T C(\eta, \tau)=\frac{Q C(\eta)+F C(\tau)+R C}{E\left[U \mid t_{0}, \tau\right]}\right\} \\
& \text { subject to } \eta>\mu_{0}, \quad t_{0} \leq \tau \leq B_{\tau} .
\end{aligned}
$$

We implemented a sequential quadratic programming (SQP) method to solve the constrained nonlinear problem, because it outperforms many other methods in terms of efficiency, accuracy, and percentage of successful solutions [20].

\section{NUMERICAL EXAMPLES}

Consider a MEMS system with a microengine subject to wear degradation. As given in Tanner et al. [24], the coefficient $c$ in (1) is $3 \times 10^{-4} \mu \mathrm{m}^{2} / \mathrm{N}$, the mean value of the radius $r$ of the pin joint is $1.5 \mu \mathrm{m}$, and the nominal value of the force applied between rubbing surfaces is $3 \times 10^{-6} \mathrm{~N}$. The standard deviations of the radius, and the applied force are assumed to be $5 \%$ of their respective mean values. The burn-in period, $t_{0}$, is assumed to be 1,000 revolutions. Using (2) and (3), the mean, and standard deviation of the wear volume at the end of the burn-in 


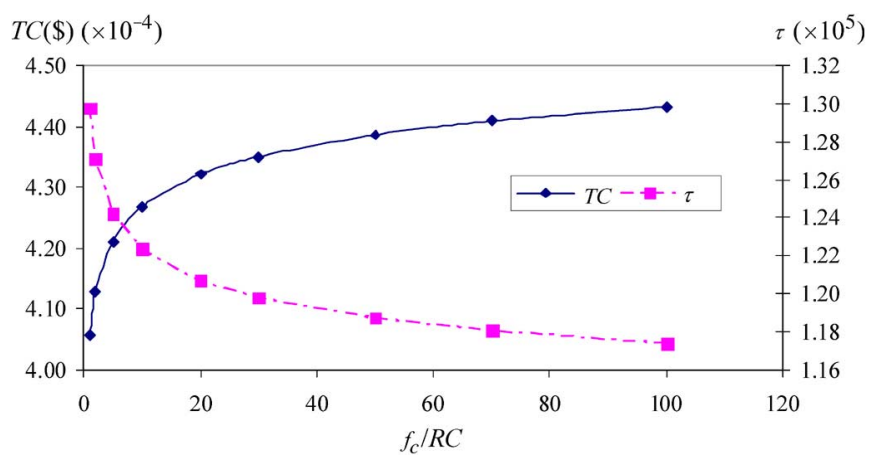

Fig. 4. Sensitivity analysis of $T C$, and $\tau$, on $f_{c} / R C$.

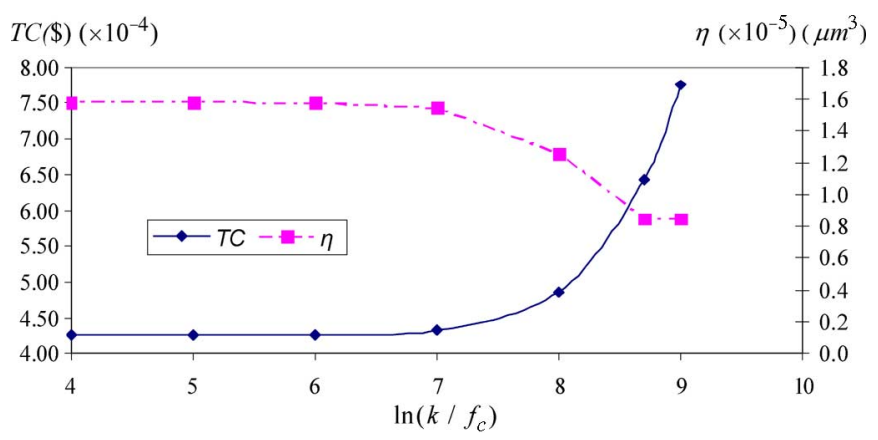

Fig. 5. Sensitivity analysis of $T C$, and $\eta$, on $\ln \left(k / f_{c}\right)$.

procedure are $8.4823 \times 10^{-6} \mu \mathrm{m}^{3}$, and $6.0016 \times 10^{-7} \mu \mathrm{m}^{3}$, respectively. The microengine experiences "soft" failures when the wear volume of material reaches a critical threshold, $H$, which is $0.00125 \mu \mathrm{m}^{3}$. The following cost parameters are used to illustrate this example. The coefficient, $k$, in the quality loss function is set to be $10^{10}$. The cost to inspect the microengine at the manufacturing phase is assumed to be $\$ 0.1$ per unit, and the scrap/rework cost of a nonconforming unit is $\$ 20$. The replacement cost of the microengine is $\$ 50$, and the cost of failure is assumed to be $\$ 1,000$. The microengine has to be replaced before $10^{5}$ revolutions, which is the upper bound of the replacement interval.

Using SQP methods provided by MATLAB, the optimal solution is obtained, which indicates that the upper specification limit should be set at $1.5461 \times 10^{-5} \mu \mathrm{m}^{3}$, and the microengine should be replaced every $1.2068 \times 10^{5}$ revolutions. The resultant minimum total cost per expected revolution, $T C$, is about $\$ 4.32 \times 10^{-4} /$ revolution.

\section{A. Sensitivity Analysis}

Sensitivity analysis was also performed to observe the effects of model parameters on optimal solutions. The parameters that we are interested in include the ratio between the cost of failure per unit and the replacement cost, $f_{c} / R C$; the ratio between the coefficient in the quality loss function and the cost of failure per unit, $k / f_{c}$; the critical threshold value, $H$; and the burn-in time, $t_{0}$. The results are shown in Figs. 4 to 7, respectively. It can be observed how the optimal solution changes as each parameter changes.

The ratio $f_{c} / R C$ indicates the relative magnitude of the failure cost to the replacement cost. When $f_{c} / R C$ increases from 1 to 100 (keeping $R C$ as a constant) as shown in Fig. 4,

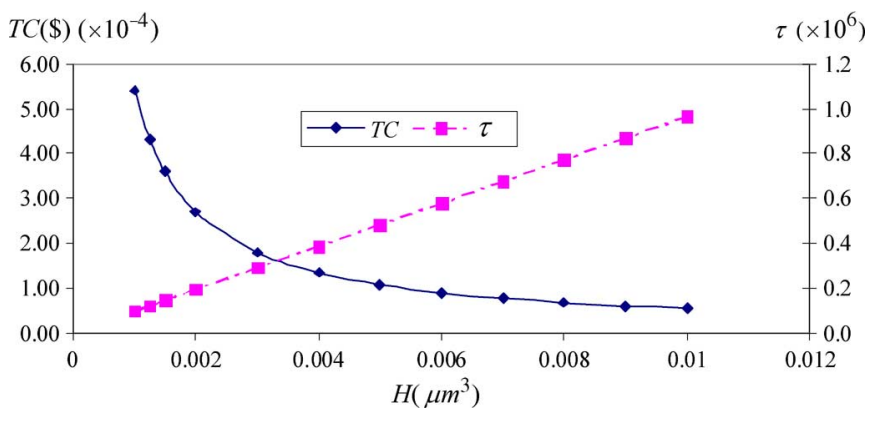

Fig. 6. Sensitivity analysis of $T C$, and $\tau$, on $H$.

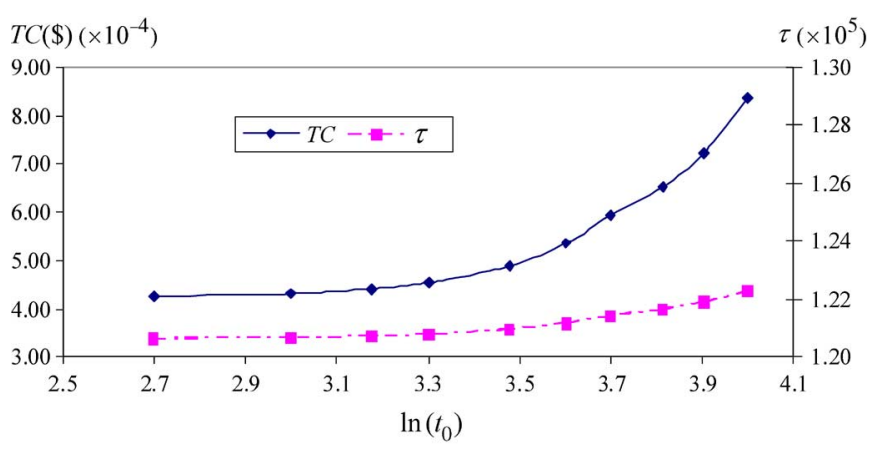

Fig. 7. Sensitivity analysis of $T C$, and $\tau$, on $\ln \left(t_{0}\right)$.

the expected total system cost rate increases from $\$ 4.06 \times 10^{-4}$ to $\$ 4.43 \times 10^{-4}$, and the optimal replacement interval decreases from $1.2978 \times 10^{-5}$ to $1.1737 \times 10^{5}$ revolutions. It suggests that microengines should be replaced more frequently as the failure cost increases, while the replacement cost keeps the same.

The ratio between $k$ and $f_{c}$ represents the relative magnitude between quality loss and failure cost. As shown in Fig. 5, when the ratio between $k$ and $f_{c}$ increases from $10^{4}$ to $10^{9}$ (keeping $f_{c}$ as a constant), the expected total system cost rate increases from $\$ 4.26 \times 10^{-4}$ to $\$ 7.76 \times 10^{-4}$, and the upper specification limit of wear volume reduces from $1.5820 \times 10^{-5} \mu \mathrm{m}^{3}$ to $8.4823 \times$ $10^{-6} \mu \mathrm{m}^{3}$. The result indicates that, as $k$ increases, a larger fraction needs to be scrapped or reworked to lower down the cost due to quality loss.

When the critical threshold value, $H$, increases from $0.001 \mu \mathrm{m}^{3}$ to $0.01 \mu \mathrm{m}^{3}$ as shown in Fig. 6, the expected total system cost rate decreases from $\$ 5.41 \times 10^{-4}$ to $\$ 5.36 \times 10^{-5}$, and the replacement interval increases linearly from $9.6547 \times 10^{4}$ to $9.6530 \times 10^{5}$ revolutions. This result suggests that the threshold value has a significant effect on the determination of the replacement interval.

As presented in Fig. 7, when the burn-in time, $t_{0}$, increases from 500 to 10,000 revolutions $\left(\ln \left(t_{0}\right)\right.$ increases from 2.7 to 4$)$, then the replacement interval increases slightly from $1.2065 \times$ $10^{5}$ to $1.2230 \times 10^{5}$ revolutions, and the total cost per unit increases from $\$ 4.26 \times 10^{-4}$ to $\$ 8.38 \times 10^{-4}$. It implies that a shorter burn-in period should be applied to minimize the total system cost, while the burn-in cost is not incorporated into the system cost. It suggests a potential research direction to simultaneously determine the burn-in time while considering the associated cost. 


\section{CONCLUSIONS}

This study proposes a mathematical model to jointly determine inspection and preventive replacement policies for the surface-micromachined microengines subject to wear degradation, which is a major failure mechanism in MEMS devices. For the microengine example, the optimal specification limit for the inspection \& the replacement interval are determined by optimizing MEMS quality and reliability simultaneously.

While illustrated using one specific microengine for die-level reliability, the proposed model can be extended to a broader range of MEMS devices that experience wear degradation between rubbing surfaces. For example, a MEMS system with several homogenous or heterogeneous degradation components presents more challenging issues on modeling the interactions between components and system reliability. Furthermore, for the reliability of a final MEMS product, all aspects of fabrication, packaging, system integration, and manufacturing must be considered.

\section{APPENDIX}

DERIVING EXPECTED UsAge Time, AND the pdf of FAILURE TIME

The expected usage time, $E\left[U \mid t_{0}, \tau\right]$, is

$$
\begin{aligned}
E\left[U \mid t_{0}, \tau\right] & =\int_{0}^{\tau-t_{0}} R\left(t+t_{0} \mid t_{0}\right) d t \\
& =\frac{1}{R\left(t_{0}\right)} \int_{0}^{\tau-t_{0}} R\left(t+t_{0}\right) d t \\
& =\frac{1}{R\left(t_{0}\right)} \int_{t_{0}}^{\tau} R\left(t^{\prime}\right) d t^{\prime} \\
& =\frac{1}{R\left(t_{0}\right)}\left(\tau R(\tau)-t_{0} R\left(t_{0}\right)+\int_{t_{0}}^{\tau} t f_{T}(t) d t\right) .
\end{aligned}
$$

Using (9), the pdf of the failure time, $f_{T}(t)$, is derived as

$$
\begin{aligned}
f_{T}(t) & =-\frac{d R(t)}{d t} \\
& =-\phi\left(\frac{H-\mu(t)}{\sigma(t)}\right)\left(\frac{1}{\sigma(t)^{2}}(b t(-a)-(H-a t)(b))\right) \\
& =\frac{H b}{b^{2} t^{2}} \phi\left(\frac{H-\mu(t)}{\sigma(t)}\right) \\
& =\frac{H}{t \sigma(t)} \phi\left(\frac{H-\mu(t)}{\sigma(t)}\right) \\
& =\frac{H}{\sqrt{2 \pi} b t^{2}} e^{-\frac{(H-a t)^{2}}{2 b^{2} t^{2}}}
\end{aligned}
$$

where $\frac{a}{b=\sqrt{(2 \pi c)^{2}\left(\sigma_{r}^{2} \sigma_{F}^{2}+\sigma_{r}^{2} \mu_{F}^{2}+\mu_{r}^{2} \sigma_{F}^{2}\right)}}$.

\section{ACKNOWLEDGMENT}

The authors would like to thank Dr. Danelle Tanner from Sandia National Laboratories for her review of the original manuscript and her insightful comments.

\section{REFERENCES}

[1] M. Ahmad and A. K. Sheikh, "Bernstein reliability model: Derivation and estimation of parameters," Reliability Engineering, vol. 8, pp. 131-148, 1984.

[2] S. J. Bae and P. H. Kvam, "A change-point analysis for modeling incomplete burn-in for light displays," IIE Trans., vol. 38, no. 6, pp. 489-498, 2006.

[3] M. Boulanger and L. A. Escobar, "Experiment design for a class of accelerated degradation tests," Technometrics, vol. 36, no. 3, pp. 260-272, 1994.

[4] A. Drapella and S. Kosznik, "Combining preventive replacement and burn-in procedures," Quality and Reliability Engineering International, vol. 18, no. 5, pp. 423-427, 2002.

[5] Q. Feng, "Integrated Statistical and Optimization Strategies for the Improvement of Six Sigma Methodology," PhD Dissertation, University of Washington, Seattle, WA, 2005.

[6] Q. Feng and K. C. Kapur, "Economic development of specifications for $100 \%$ inspection based on asymmetric quality loss functions," IIE Trans., vol. 38, no. 8, pp. 659-669, 2006.

[7] Q. Feng and D. W. Coit, "Simultaneous quality and reliability optimization for systems composed of degrading components," in Proceedings of Industrial Engineering Research Conference, Nashville, TN, May 19-23, 2007.

[8] A. Grall, L. Dieulle, C. Berenguer, and M. Roussignol, "Continuoustime predictive-maintenance scheduling for a deteriorating system," IEEE Trans. Reliability, vol. 51, no. 2, pp. 141-150, 2002.

[9] R. Jiang and A. K. S. Jardine, "An optimal burn-in preventive-replacement model associated with a mixture distribution," Quality and Reliability Engineering International, vol. 23, pp. 83-93, 2007.

[10] V. R. Joseph and I. T. Yu, "Reliability improvement experiments with degradation data," IEEE Trans. Reliability, vol. 55, no. 1, pp. 149-157, 2006.

[11] J. P. Kharoufeh, "Explicit results for wear processes in a Markovian environment," Operations Research Letters, vol. 31, pp. 237-244, 2003.

[12] J. P. Kharoufeh and S. M. Cox, "Stochastic models for degradationbased reliability," IIE Trans., vol. 37, pp. 533-542, 2005.

[13] W. Kuehnel and S. Sherman, "A surface micromachined silicon accelerometer with on-chip detection circuitry," Sensors and Actuators, vol. 45 , no. 1, pp. 7-16, 1994.

[14] W. Kuo, "Challenges related to reliability in Nano electronics," IEEE Trans. Reliability, vol. 55, no. 4, pp. 569-570, 2006.

[15] H. Liao, E. A. Elsayed, and L. Y. Chan, "Maintenance of continuously monitored degrading systems," European Journal of Operational Research, vol. 175, pp. 821-835, 2006.

[16] C. J. Lu and W. Q. Meeker, "Using degradation measures to estimate a time-to-failure distribution," Technometrics, vol. 35, no. 2, pp. 161-174, 1993.

[17] H. Lu, W. J. Kolarik, and S. S. Lu, "Real-time performance reliability prediction," IEEE Trans. Reliability, vol. 50, no. 4, pp. 353-357, 2001.

[18] S. Lu, Y. C. Tu, and H. Lu, "Predictive condition-based maintenance for continuously deteriorating systems," Quality and Reliability Engineering International, vol. 23, pp. 71-81, 2007.

[19] W. Q. Meeker, L. A. Escobar, and C. J. Lu, "Accelerated degradation tests: Modeling and analysis," Technometrics, vol. 40, no. 2, pp. 89-99, 1998.

[20] J. Nocedal and S. J. Wright, Numerical Optimization, 2nd ed. New York: Springer-Verlag, 2006.

[21] K. A. Peterson, P. Tangyunyong, and A. A. Pimentel, "Failure analysis of surface-micromachined microengines," in Proceedings of SPIE, the Materials and Device Characterization in Micromachining Symposium, C. R. Friedrich and Y. Vladimirsky, Eds., Santa Clara, CA, Sep. 21-22, 1998, vol. 3512, pp. 190-200.

[22] A. D. Romig and P. J. McWhorter, "Intelligent micromachines: Opportunities and challenges of the next Si revolution (invited paper)," Semicon, 2001a, Europe.

[23] A. D. Romig and P. J. McWhorter, "Opportunities and challenges in MEMS commercialization," Vacuum Coat Technology Magazine, $2001 \mathrm{~b}$. 
[24] D. M. Tanner, W. M. Miller, K. A. Peterson, M. T. Dugger, W. P. Eaton, L. W. Irwin, D. C. Senft, N. F. Smith, P. Tangyunyong, and S. L. Miller, "Frequency dependence of the lifetime of a surface micromachined microengine driving a load," Microelectronics Reliability, vol. 39, pp. 401-414, 1999a.

[25] D. M. Tanner, J. A. Walraven, L. W. Irwin, M. T. Dugger, N. F. Smith, W. M. Miller, and S. L. Miller, "The effect of humidity on the reliability of a surface micromachined microengine," in Proceedings of IEEE International Reliability Physics Symposium, 1999b, pp. 189-197.

[26] D. M. Tanner and M. T. Dugger, "Wear mechanisms in a reliability methodology," in SPIE's Proceedings, San Jose, CA, 2003, vol. 4980, Reliability, Testing, Characterization of MEMS/MOEMS, pp. 22-40.

[27] S. T. Tseng, M. Hamada, and C. H. Chiao, "Using degradation data from a factorial experiment to improve fluorescent lamp reliability," Journal of Quality Technology, vol. 27, no. 4, pp. 363-369, 1995.

[28] M. T. Todinov, "Reliability analysis and setting reliability requirements based on the cost of failure," International Journal of Reliability, Quality and Safety Engineering, vol. 11, no. 3, pp. 273-299, 2004.

[29] N. Unal and R. Weschsung, "Inkjet printheads: An example of MST market reality," Micromachine Devices, vol. 3, no. 1, pp. 1-6, 1998.

[30] J. A. Walraven, T. J. Headley, A. N. Campbell, and D. M. Tanner, "Failure analysis of worn surface micromachined microengines," in SPIE Proceedings on Micromachining and Microfabrication, Santa Clara, CA, September 20-22, 1999, pp. 30-40.

[31] H. Yu and C. H. Chiao, "An optimal designed degradation experiment for reliability improvement," IEEE Trans. Reliability, vol. 51, no. 4, pp. 427-433, 2002.
Hao Peng is a Ph.D. Student in the Department of Industrial Engineering at the University of Houston. She received a BS degree in industrial engineering from Tsinghua University, Beijing, China in 2006. Her research interests include reliability \& maintenance engineering, and optimization, especially degradation-based modeling and analysis. She is a member of INFORMS, and ASQ.

Qianmei Feng is an Assistant Professor in the Department of Industrial Engineering at the University of Houston. She received a Ph.D. degree in industrial engineering from the University of Washington, Seattle, WA in 2005. Her research has been in reliability and quality engineering; and applications in manufacturing, healthcare, and transportation systems. She has published a dozen papers in journals such as IIE Transactions, Reliability Engineering and System Safety, International Journal of Advanced Manufacturing Technology, and Risk Analysis. She is a member of IIE, INFORMS, ASQ, and Alpha Pi Mu.

David W. Coit (M'03) is an Associate Professor in the Department of Industrial \& Systems Engineering at Rutgers University. He received a BS degree in mechanical engineering from Cornell University, an MBA from Rensselaer Polytechnic Institute, and MS \& Ph.D. degrees in industrial engineering from the University of Pittsburgh. In 1999, he was awarded a CAREER grant from NSF to study reliability optimization. He also has over ten years of experience working for IIT Research Institute (IITRI), Rome, NY, where he was a reliability analyst, project manager, and an engineering group manager. His current research involves reliability prediction \& optimization, risk analysis, and multi-criteria optimization considering uncertainty. $\mathrm{He}$ is a member of IIE, and INFORMS. 